\title{
Agricultural research for nutrition outcomes - rethinking the agenda
}

\author{
John McDermott ${ }^{1}$ - Nancy Johnson ${ }^{1} \cdot$ Suneetha Kadiyala $^{2}$ - Gina Kennedy ${ }^{3}$. \\ Amanda J. Wyatt ${ }^{1}$
}

Received: 21 January 2015 / Accepted: 30 March 2015 / Published online: 14 May 2015

(C) The Author(s) 2015. This article is published with open access at Springerlink.com

\begin{abstract}
Agriculture and food are assumed to be critical determinants of stunting and micronutrient deficiency. However, agriculture research for development has not translated as expected into better nutrition outcomes. We argue that to do so, agriculture research needs to be fundamentally changed, from the current emphasis on supply-side production and productivity goals to understanding consumption and addressing factors that can improve diet quality. Some of the research will be to improve the efficiency of supply for more nutritious foods. Other research will need to focus on factors that promote diet quality rather than focus on food security goals through stocks of staple cereals. Because of its importance in low-income, high-burden countries, agriculture can also contribute more effectively to multisectoral nutrition-sensitive development strategies and programs. Critical roles for agricultural research in multisectoral actions will be better metrics, indicators and research studies for diet quality and better evaluation methods both randomized trials for specific interventions and contribution analysis through theories of change for more complex multisectoral system interventions to prevent stunting and micronutrient deficiencies. To achieve improvements in nutrition outcomes at scale, researchers must engage in new partnerships. In food systems, these partnerships must include more
\end{abstract}

Special section series Strengthening the links between nutrition and health outcomes and agricultural research

John McDermott

j.mcdermott@cgiar.org

1 International Food Policy Research Institute, 2033 K Street NW, Washington, DC 20006, USA

2 London School of Hygiene and Tropical Medicine, Leverhulme Centre for Integrative Research on Agriculture and Health, 36 Gordon Square, London WC1H OPD, UK

3 Bioversity International, Via dei Tre Denari, 472/a, 00057 Maccarese, Fiumicino, Italy disciplines from agriculture and food science through economics and social science to business and delivery science. Food system researchers will also need to engage more with value chain actors and policy makers. Current efforts to improve nutrition outcomes at scale are severely hampered by data and evidence gaps that prevent better decisions and faster learning.

Keywords Agriculture-nutrition $\cdot$ Evidence $\cdot$ Research $\cdot$ Diet quality $\cdot$ Stunting

\section{Current conversation in agricultural research for development}

The goals of international agricultural research for development are changing. Today, development-oriented investments, including agriculture, need to show how they contribute to higher-level goals such as poverty reduction, better nutrition and environmental sustainability. This is especially true of CGIAR, a global partnership that unites organizations engaged in research for a food secure future. ${ }^{1}$ A major goal of recent CGIAR reforms is to better align research, carried out by the 15 CGIAR centers with hundreds of partners, to contribute to these goals. The creation of the CGIAR Research Program on Agriculture for Nutrition and Health (A4NH) ${ }^{2}$ reflects CGIAR's commitment to enhancing the ability of agriculture to contribute to better nutrition and health.

Key nutrition goals on the global development agenda include addressing micronutrient deficiencies among women and children and stunting among children (growth retardation). It is generally accepted that the main determinants of nutrition are food, health and care (UNICEF 1990). Agriculture contributes to improved nutrition primarily, though not exclusively, through food. Both quality and quantity of food

\footnotetext{
$\overline{1}$ http://www.cgiar.org/

2 http://www.a4nh.cgiar.org/
} 
matter for good nutrition and health. Historically, agricultural research has focused on improving food security through improvements in yields of staple commodities. Relatively little attention has been paid to improving the quality of diets, and this is the major gap that A4NH seeks to address. This new focus on diets - the types and amounts of food consumed by individuals - as an outcome for agricultural research has implications for the types of research that should be conducted, where, and with what partners.

In addition to enhancing agriculture's contribution to improved diet quality, achieving impacts on the higher level nutrition goals will require understanding how best to align agriculture's contributions with those of other sectors working on the other underlying determinants. In 2013, at the Nutrition for Growth Summit, USD 23 billion was committed by governments, nongovernmental organizations (NGOs), and the private sector for nutrition actions - USD 4 billion for nutrition-specific actions and USD 19 billion for nutrition-sensitive actions. Subsequently, a Nutrition for Growth Compact was signed by these parties. ${ }^{3}$ This concept of nutrition-sensitive operates on the assumption that the achievement of nutrition goals is more likely when we leverage other development sectors, such as agriculture, social protection, and water and sanitation, to incorporate explicit nutrition objectives in their research and programs. This concept has gained traction, as evidenced by the Scaling up Nutrition (SUN) movement and the Amsterdam Initiative against Malnutrition, and illustrates the importance of understanding and embracing multisectoral partnership models if we are to reach nutrition goals.

This paper examines promising opportunities for agricultural research in CGIAR to enhance its contribution to improving nutrition. The next section looks at the research issues around improving diets and enhancing multisectoral collaboration. Next, we discuss the implications of a nutrition objective for how agricultural research is monitored and evaluated, including both the pathways through which agricultural research outputs can contribute to improvements in diets and nutrition outcomes, and key indicators for tracking outcomes along the pathway. Then we outline the new partnership opportunities a nutritionsensitive agricultural research and development agenda will need to embrace. The last section concludes with final thoughts on how to move this agenda forward.

\section{New nutrition-sensitive agricultural research to meet nutrition challenges}

Agricultural research should address improvements in diet quality, and there is also scope for research on how to better

\footnotetext{
${ }^{3}$ A copy of the Nutrition for Growth Compact is available online at https://www.gov.uk/government/uploads/system/uploads/attachment data/file/248760/Endorserscompact_update7_10_2013.pdf.
}

align policies and investments with other sectors to reduce stunting and reduce micronutrient deficiencies. For CGIAR, new approaches will be required. The first is to put greater emphasis on diet quality, which can encompass concepts of nutrient adequacy (adequate intake of fat, protein, carbohydrates, vitamins and minerals), dietary moderation and balance, as well as food safety (Ruel 2003). This will require a much greater emphasis on understanding healthy consumption and the drivers for improving diet quality and safety. Ideally, this will be linked to considerations of the sustainability of diets so that diets are both healthy and sustainable. In this section we will focus on healthy diets. The second major challenge is how agricultural research for development can coordinate with other development sectors to support accelerated actions to decrease stunting and micronutrient deficiencies. This will include both improving public sector programs and investments and linking these effectively to actions by the private sector and civil society.

Agricultural research needs to help us understand the constraints and opportunities on both the supply side - promoting production and delivery of a variety of safe and nutritious foods - and the demand side, as people must be made aware of the importance of eating diverse diets. This is where research on demand creation including social marketing strategies are needed to help consumers embrace and maintain healthy eating (World Bank 2014). For CGIAR, shifting research from an almost exclusively supply side agenda to more emphasis on consumption and demand, including policies and social norms that guide consumer preferences, is essential to meeting the goals of improving nutrition.

\section{Reshaping agricultural research to contribute to affordable, nutritious and safe diets}

For CGIAR, nutrition-sensitive agricultural research must shift to understanding healthy diets - how they have changed and the supply and demand side drivers. ${ }^{4}$ We need more consumption studies, including tracking what is commonly known as the dietary transition and assessing key determinants associated with consumption such as price and availability. This constitutes a major and overdue shift in research, given that in most low- and middle-income countries (LMIC), farmers are growing less food for their own consumption and are increasingly more influenced by demand-side factors in agricultural decisions. In this rapidly changing "productionconsumption" relationship, we need research that improves our understanding of markets and how different types of market interventions (knowledge, institutional arrangements,

\footnotetext{
${ }^{4}$ For a proposed framework to identify, design and evaluate nutritionsensitive value chain interventions, see the draft publication from Gelli et al. (2014) available online at http://www.a4nh.cgiar.org/files/2012/07/ Value-Chains-for-Nutrition-Framework-V-1.1.pdf.
} 
enabling policy and investments) support the availability and accessibility of a more diverse food basket. This research will help us identify both the income opportunities for poor people to participate in higher value markets as well as how to improve the diversity, quality, and safety of foods in markets in smaller cities and towns and in rural areas.

Another research priority in this new agenda is on improving the efficiency and effectiveness of the supply of nutritious foods, particularly fruits and vegetables; animal source foods, such as milk, meat, eggs, and fish; and pulses, which include various types of beans and peas, groundnuts, and lentils, in order to improve their quality and safety and reduce their relative prices. For the value chains of individual commodities, both diet quality and sustainability need to play a greater role in how we prioritize research. Historically, productivity and production criteria have dominated commodity investment and policy decisions at international and national levels (Pinstrup-Andersen and Watson 2011).

A greater emphasis on research that contributes to improving diet quality will naturally lead CGIAR to expand its focus from the value chains of individual commodities to collaborating with others in a more holistic view of diets, whether it be through food systems, food webs, or other systematic perspectives. There will be more opportunities for research on technical innovations, particularly for perishable nutritious foods. Agricultural researchers will need to collaborate more closely with food scientists on innovations in food safety, cold chains, processing, and other solutions to post-harvest challenges. The technical research may be as much about adapting innovations from other settings as de novo innovation. For example, simple testing kits for milk hygiene have been adapted for use in quality and safety testing in informal milk value chains in Kenya and India.

A food system approach naturally leads to research that integrates technical, business, and social (including institutional) innovations - so called convergent innovation (Dubé et al. 2014). This paradigm promotes the joint goals of improving health and wealth and the participation of public, private and civil society actors. This and other innovation system approaches look to lever the power of private sector know-how with social mobilization and public policy and investments. Research into the performance of private sector food systems, public-private partnerships for more nutritious food systems, or the performance of different hybrid models of public, private and social enterprise systems will be important. The Pulse Innovation Partnership is one such innovation starting in India to support pulse-based food innovation at scale (Jha et al. 2014). Such partnerships bring together opportunities for supporting small- and medium-size enterprises with technical innovation support as well as providing them with insights into policy and market information.

Finally, food systems in LMIC are changing fast. The triple burden of malnutrition - undernutrition, micronutrient deficiencies, and overweight and obesity - is a critical issue (Ng et al. 2014). Foresight studies linking agricultural productivity with food consumption and nutrition and health outcomes are an initial place to start for CGIAR research (Headey 2013; Khoury et al. 2014), but research that improves an overall understanding of the convergence between socio-economic, nutritional and environmental sustainability factors in food systems for optimal nutrition and health outcomes is critical (Dubé et al. 2014).

\section{Agriculture as part of a multisectoral response to stunting}

Childhood stunting is largely an irreversible outcome of inadequate nutrition and frequent infections during the 1000 days window (from conception to the child's 2nd birthday), (Black et al. 2008; Black et al. 2013). It is well understood that stunting is a complex problem that requires multisectoral solutions. An updated analysis of stunting data from 116 countries suggests that one third of stunting is correlated to food and agriculture factors, one third to water and sanitation factors and one third to social factors, particularly gender (Smith and Haddad 2014). One set of sectoral actions will not solve the problem; we know we need multisectoral responses (see examples in Garrett and Natalicchio 2011). The challenge for both research and development actors, is how to design and implement multisectoral programs at scale.

One general assumption about nutrition-sensitive development is that pilot programs, demonstrated to work, can be scaled out. However, experience shows it is not so simple. Given international and national ambitions for scaling up nutrition actions for impacts at scale, we need to understand how implementation happens at scale. This has spurred strong interest in delivery science - studies on the processes, contexts, and determinants of how to deliver interventions to targeted populations - and the formation of the International Society for Implementation Science in Nutrition. ${ }^{5}$ What we can learn about implementation is very important to understanding how and why some programs achieve their goals and how to scale up such programs. Rigorous assessment of the factors tied to the successes and failures of multisectoral programs to improve nutrition are particularly important to share with decision-makers in governments, civil society, and NGOs. For example, as with almost all Indian states, Maharashtra has invested in multisectoral programs to reduce stunting and micronutrient deficiency. Historically, Maharashtra's performance in stunting reduction, and associated program evaluation indicators, has been no better than average. However, in the recent past (2006 to 2012) stunting has been dramatically reduced from 39 to $24 \%$ or approximately an average annual reduction rate of $7 \%$. These rates of stunting reduction are much higher than expected compared to the previous

\footnotetext{
${ }^{5}$ http://www.implementationsciencesociety.org/
} 
period or to other LMIC like Bangladesh or Ethiopia, for example (Haddad et al. 2014). This success has been attributed to two factors: attention to implementation, including greater efforts at training and filling all front-line implementation positions, and government and civil society leadership committed to program performance (Haddad et al. 2014).

How a supportive and enabling multisectoral environment for policy and action can be promoted to maximize the nutrition-sensitivity of agriculture is another key area for research where A4NH is contributing. The conceptual starting point for the research is based upon the enabling environment framework from the paper by Gillespie et al. (2013) in The Lancet Maternal and Child Nutrition Series. A number of ongoing studies are exploring the political economy of agriculture and agrifood systems and of policymaking and implementation processes, such as the prevailing incentives, disincentives, opportunities, constraints, trade-offs and potential synergies for strengthening the nutrition sensitivity of agriculture. A4NH is supporting the development of case studies using an approach called 'stories of change', which will be used to document the country-specific political and social processes that influence multisectoral policies and programs addressing malnutrition (Garrett et al. 2014). The lessons can help stakeholders improve their understanding about what drives impact and how multisectoral nutrition policies and processes can be promoted and sustained. ${ }^{6}$

Lastly, the multisectoral nature of the nutritionsensitive agenda has put the spotlight on the issue of data. The first annual Global Nutrition Report highlighted the current gaps in nutrition data that are necessary to evaluate country program performance (IFPRI 2014). For example, almost half of all countries cannot assess if they are on or off course for four of six key World Health Assembly monitoring targets. In countries with data, data is often outdated: $40 \%$ of the most recent child growth surveys which countries were using were more than 5 years old. A number of questions need to be addressed to improve this data monitoring and evaluation picture. One set of questions is to develop alternative methods and approaches to make data collection and analysis more feasible, reduce the costs, and improve the quality. A second set of questions relates to the cost and benefits of different types of monitoring and evaluation for assessing progress over time and across different locations, and informing policy and investment decision making. If smarter and faster progress in interventions to reduce stunting and micronutrient deficiencies are to be achieved, improved metrics and indicators and different methods for monitoring, evaluation and learning are needed.

\footnotetext{
${ }^{6}$ More information about how the stories of change approach is being used in programs such as Transform Nutrition is available online at http:// www.transformnutrition.org/2014/12/11/stories-of-change-in-nutrition/.
}

\section{Monitoring, evaluating and learning from nutrition-sensitive agricultural research and development}

There is consensus about the need for more and better evidence of the impact of different types of agricultural investments on diets and other nutrition outcomes (Berti et al. 2004; Girard et al. 2012; Leroy and Frongillo 2007; Masset et al. 2012; Randolph et al. 2007). One important source of this evidence will be evaluations of agricultural development programs. Greater attention to issues of evaluation design will be essential to be able to detect impacts. In most cases, doing this will require close collaboration with program implementers, with the latter agreeing to implement programs in such a way that appropriate participants and control groups can be identified and their outcomes compared. The outcomes of such evaluation are crucial for providing evidence for the nutrition and public health communities, however their cost means that it will be important to select programs carefully to maximize not only the potential to detect impact, but also the usefulness of the information for future action in programs, policy and research.

One way to enhance the usefulness and generalizability of the results of impact evaluations is to be sure that they are based on a clear program theory, often represented by a program impact pathway (Mayne and Stern 2013; UNEG 2013; White 2009). The impact pathway shows the links between program interventions and the series of outcomes leading ultimately to nutrition impact (Avula et al. 2013; Kim et al. 2011; Olney et al. 2009; Rawat et al. 2013). Impact pathways inform program design and implementation by ensuring that there are no gaps in the intervention logic and that all activities believed necessary to achieve the expected outcome are anticipated and included in the program. Given the multiple potential pathways between agriculture and nutrition (Gillespie et al. 2012), it is especially important to develop an impact pathway that identifies which pathways each project is expecting to influence and how.

The impact pathway can also be used during implementation to ensure that the program is being implemented as planned and to verify whether the intermediate outcomes, for example, changes in nutrition knowledge, attitudes or practices, or women's control of resources or participation in decision making, are happening as expected. Monitoring the changes along the pathway in real time - often referred to as process evaluation or operations research - is important for several reasons. First, it ensures that the program is being implemented as intended, which is crucial in interpreting any impact results. Program implementers might also find it useful to know which aspects of implementation tend to be most challenging to implement as planned and why, so that they can plan accordingly. 
Second, documenting intermediate outcomes along the pathway is especially important for understanding why a program may not have the intended impact. The program evaluation is basically a test of the program theory which can only be done if there is a way to know which parts of the theory worked as expected and which did not. Finally, not only can having a good impact pathway increase the amount that can be learned from an evaluation, it can also help make the lessons accessible and useful to a broader audience. The more detail that is available on the program theory, the easier it is for others to see why a program worked in a specific context and to use that information to inform decisions about how it might need to be adapted for another context, which is especially important for scaling up.

Diet quality and other nutrition-related outcomes are new objectives for CGIAR research, and it cannot be assumed that the kinds of research outputs that were successful when measured against traditional objectives such as productivity or income will also be effective in delivering nutrition-related outcomes. Working back from intended outcomes to current activities is also useful for planning and managing nutritionsensitive agricultural research. While in some cases researchers and partners have clearly identified these pathways, in most cases they are implicit. The process of making the pathways more explicit can reveal logical inconsistencies, evidence and capacity gaps, or the critical roles of previously unrecognized actors. As their research progresses, CGIAR research will need to address these gaps, as well as monitor their progress along their pathways, and ultimately show that their research has contributed to development outcomes.

One example for how research programs can use impact pathways and theories of change is provided by HarvestPlus, which breeds micronutrient enhanced varieties of important staple crops and conducts related research on how to develop and disseminate these innovations. To look more closely at what is needed to have impact on the ground with biofortified varieties, $\mathrm{A} 4 \mathrm{NH}$ and HarvestPlus developed theories of change for three target countries (Johnson 2014). See Fig. 1 for an example of the theory of change developed for orange maize in Zambia. The types of behavior changes and development outcomes are similar to the program theory developed by Masset et al. (2012) in their systematic review of agriculture-nutrition interventions. The ultimate goal of biofortification is to improve micronutrient status by reducing the prevalence of inadequate dietary micronutrient intakes. Home consumption within farm households is expected to be the major pathway through which target consumers (members of rural farm households) and especially target beneficiaries (micronutrient-deficient women and children) will obtain biofortified crops. The market is, however, expected to play a role both in reaching target consumers and in making biofortified varieties commercially sustainable. Farmers are assumed to access and adopt biofortified varieties and to consume them in their households and sell any surplus on the market.
Fig. 1 Theory of change for provitamin A maize in Zambia. Source: adapted from Johnson, Guedenet, and Saltzman (2015), p. 8

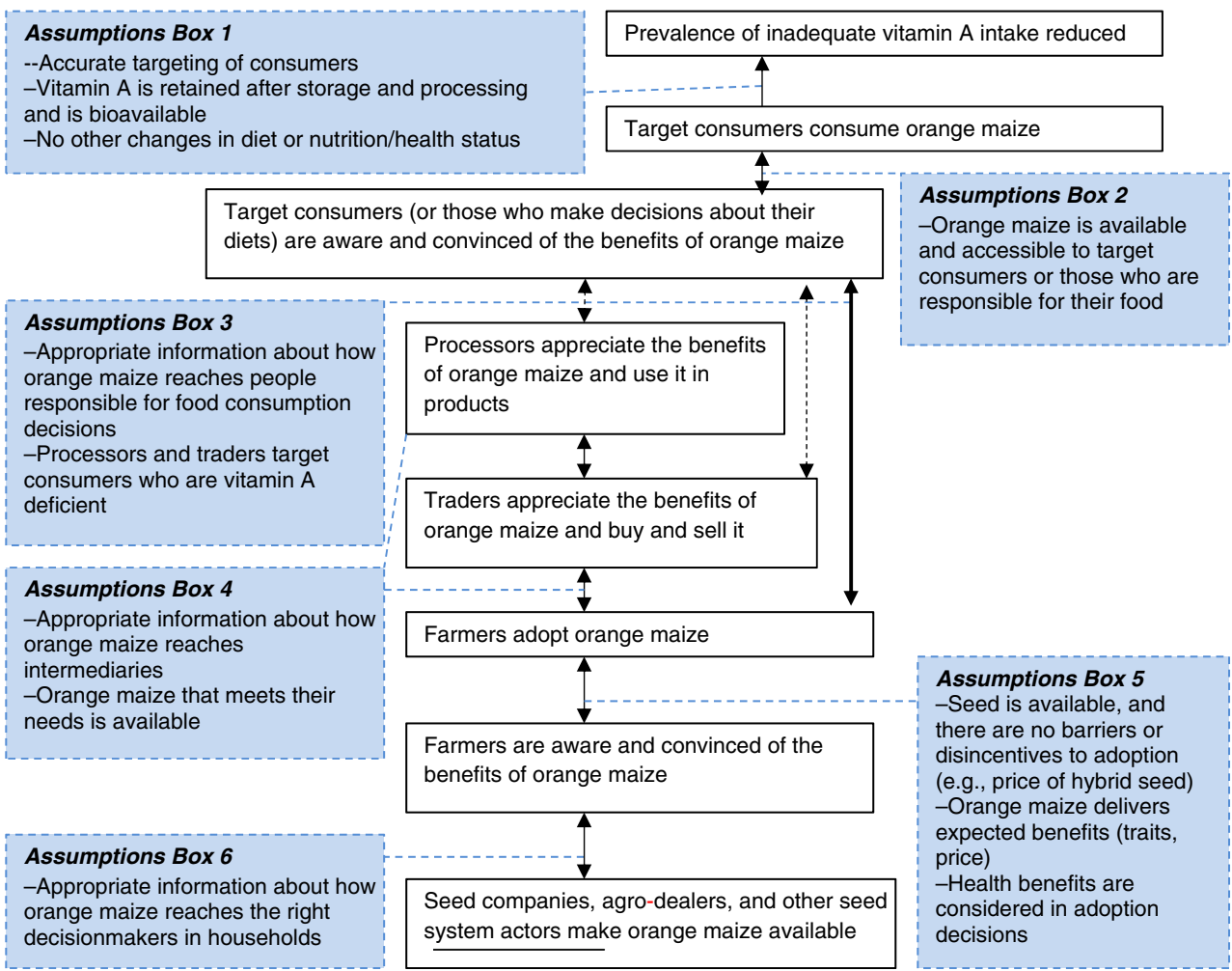


For each of these outcomes, the theory of change identifies the key assumptions that must hold in order for the links between outcomes to occur. For each of these assumptions, evidence was assembled about whether the assumption was likely to hold. In many cases, this evidence was available from past HarvestPlus research, for example on retention and bioavailability of micronutrients in crops under local conditions (see Assumption Box 1 in Fig. 1), from consumer acceptance studies (see Assumption Box 3 in Fig. 1), or from farmer evaluation of crop varieties (see Assumption Box 5 in Fig. 1). Important gaps that were identified related to how target consumers accessed the crop - through which combinations of own production and markets - and who in the household makes decisions related to production, sale, and consumption. The results of the exercise for all three countries are summarized in Table 1. More information from research or from program monitoring can help fill gaps and improve impact and learning (Table 2).

Theory of change is also being used to guide work on improving food safety in informal dairy value chains. Increased consumption of meat, milk, eggs, and fish among poor consumers in developing countries has the potential to improve diets as well as drive pro-poor economic development. Achieving this outcome will require not only making animal source foods more available and accessible to target consumers, but also maintaining or improving their safety. Animal source foods are considered to be the main cause of food borne disease, and the poor generally purchase meat, milk and fish in informal or wet markets (Grace et al. 2008; Vorley 2013). Achieving increased consumption of safer meat, milk, and fish by target consumers will require addressing a range of outcomes along the impact pathway and for different target groups in an integrated way (Fig. 2). To accomplish this, A4NH is working closely with the CGIAR Research Program on Livestock and Fish. ${ }^{7}$

Past research has identified an institutional innovation - a training, certification and branding scheme for informal value chain actors - designed to improve the safety of animal source foods sold in informal markets (Omore and Baker 2011). The innovation was developed as part of a dairy research project in Kenya, and the approach has been adapted and tested in other contexts. As in the case of HarvestPlus, the theory of change identifies the expected outcomes along the pathway from research to impact, explains the links and summarizes the evidence that supports underlying assumptions and risks. Working through the theory of change suggests possible approaches to addressing specific issues in a given context, and at different stages of the research and implementation process. For example, more research is needed to understand and test the efficacy and effectiveness of the intervention in different contexts and fill evidence gaps, especially

\footnotetext{
${ }^{7}$ http://livestockfish.cgiar.org/
}

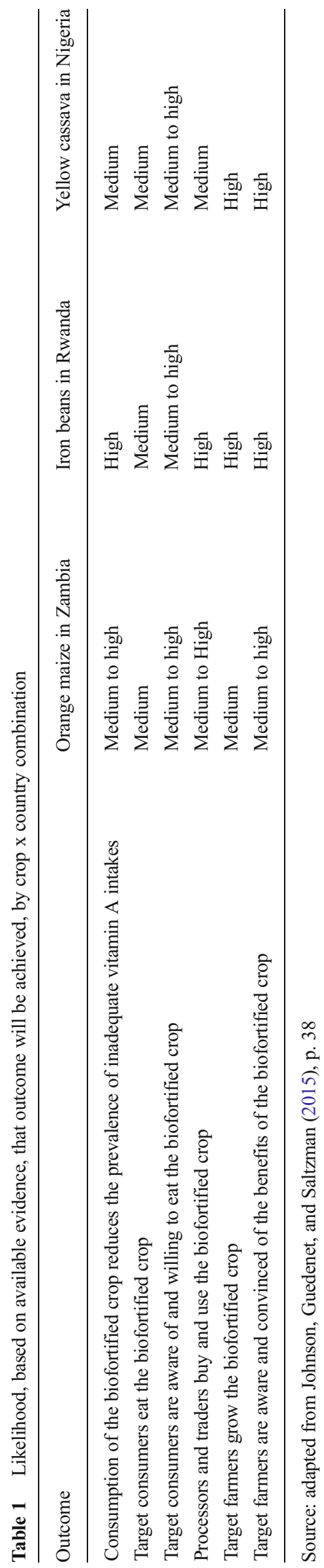


related to the impact of such schemes on consumer behavior. To date most pilot studies have focused on traders' participation and impact on product quality.

The work on theories of change made explicit the need to think not only about how the intervention, if implemented, would lead to food safety and nutrition outcomes, but also about what kinds of partners - NGOs, government regulators, private sector certification agencies, trader associations - would have the incentive to implement the training programs, in which types of value chain or economic and policy contexts. The feasibility and sustainability of impact at scale will depend on the cost-effectiveness of the intervention and the performance of the implementing organization. More attention to these parts of research is needed.

\section{What needs to be measured - indicators and targets for impact}

As the previous section suggests, what needs to be measured and monitored is not a simple question since there are outcomes all along the impact pathway that could be usefully tracked at different times for different purposes. While monitoring and evaluating the impacts of agricultural research for development on nutrition goes beyond nutrition outcomes and in some cases may not even require measuring nutrition outcomes depending on which segment of the impact pathway the analysis is focused - there are two areas of indicators that are especially important for monitoring the impact of agricultural research on nutrition outcomes. These are diets and gender.

\section{Measuring diet quality}

Diet quality can encompass concepts of nutrient adequacy (adequate intake of fat, protein, carbohydrates, vitamins and minerals), dietary moderation and balance (Ruel 2003) as well as food safety. There are different methods, which can be used to measure food intake directly or serve as proxies. The gold standard of dietary intake is the 24-h recall method of food intake measured at the level of an individual (as compared to household or even larger aggregate levels), (FAO 2003). The 24-h recall method is not widely employed in large scale surveys and data derived from this method is particularly lacking in developing countries due to the time and resources required to collect and analyze quantitative food intake data. There are many alternative ways to collect and analyze food consumption information using indicators that are proxies for actual caloric intake and/or diet quality (WFP 2008). Some examples of food-based indicators at national, household and individual-level of data collection are shown in Table 3.

Food Balance Sheet data, collected by FAO since 1960, report estimates of national level food availability. To address 
Fig. 2 Overview theory of change (TOC) for improving nutrition and health in livestock value chains. Source: Adapted from Johnson 2014

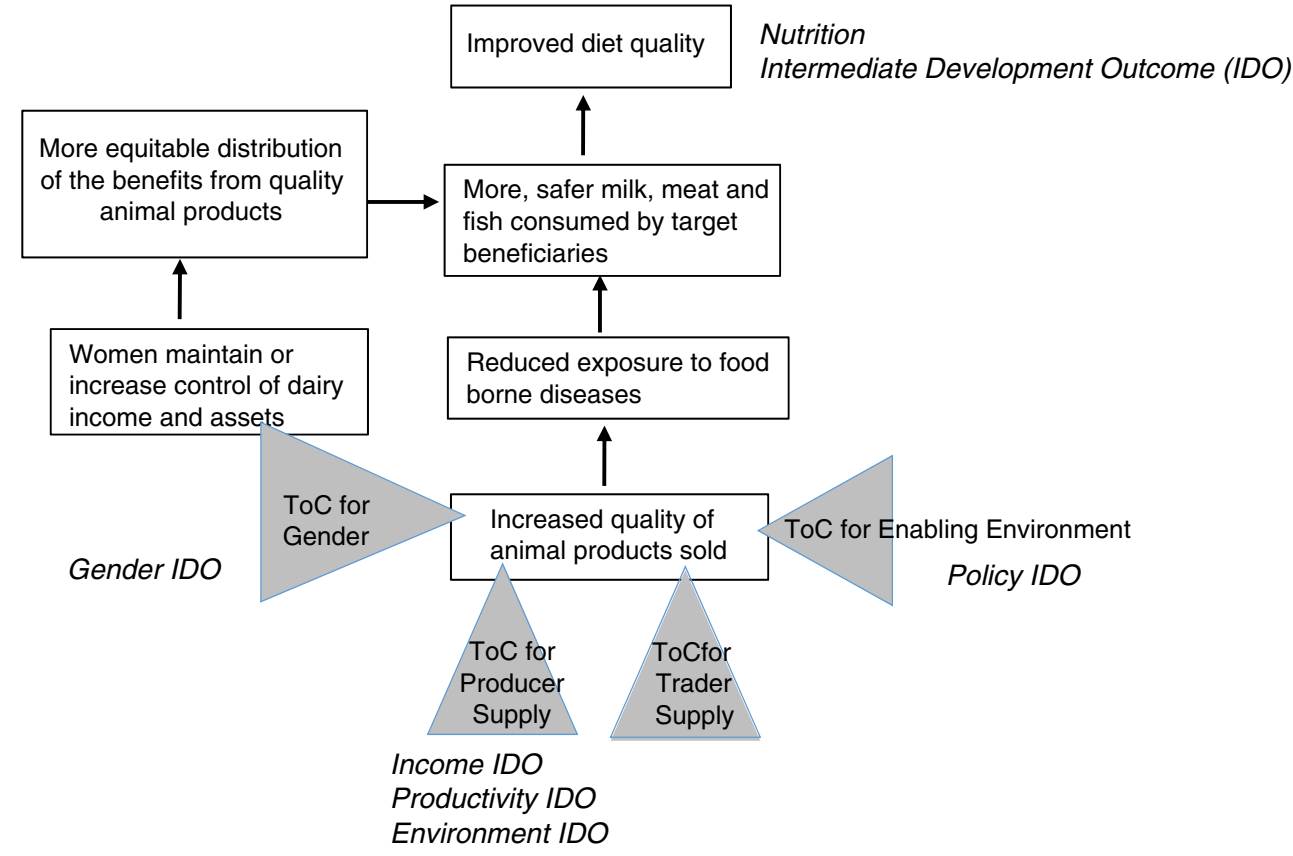

the agriculture-nutrition agenda, these data can be useful to identify broad time series trends in quality of national level per capita availability, as for example the trend in increase in per capita availability of meat, fish and poultry (FAO 2006) or edible fats and oils (Popkin 2006). The interpretation of the data is limited to national level assessment and cannot be used to infer the distribution of adequacy of intakes for individuals within the population.

\section{Indicators for diet quality}

Household level information on food intake has been used most widely in food security and vulnerability assessments, the Household Dietary Diversity Score (HDDS) has been most commonly used in USAID-funded food security programs, while the Food Consumption Score (FCS) is used by the World Food Programme in Comprehensive Food Security and Vulnerability Analysis (CSFVA) and similar food security surveys. Both indicators offer the advantage of a standardized, replicable methodology that can be used for temporal and international comparisons and both are considered good proxy indicators for household food consumption (Kennedy et al. 2010). The validation of these indicators has been limited to household dietary energy intakes which, strictly interpreted, reflect quantity of food consumed and do not capture diet quality or adequacy of the diet in terms of nutrients other than dietary energy (e.g., adequate intake of vitamins and minerals).

The most commonly used individual indicators of dietary diversity involve counting the number of food groups consumed by the individual over a reference period of the previous day. The two most frequently used individual indicators of dietary diversity, Minimum Dietary Diversity (MDD) for children 6-23 months of age and Women's Dietary Diversity, have been validated as proxy indicators of the nutrient adequacy of the diet (Arimond et al. 2010; FAO and IRD 2014; WHO 2008). Many studies have shown positive associations between dietary diversity scores and nutritional outcomes (Ruel et al. 2013b) and dietary diversity indicators are collected by large scale programs such as the Demographic and Health Surveys, Feed the Future, and CGIAR. Guidance on how to collect information and how to construct indicators of dietary diversity are available from WHO for children 623 months of age (WHO 2008; WHO 2010) and from FAO for women of reproductive age (FAO 2011).

Dietary patterns in developing countries show increasing reliance on processed and prepared foods. As food systems become more globalized and problems related to over consumption and diet-related non communicable disease increase, there is a pressing need to expand the set of indicators used to assess diet quality. A report on the double burden of malnutrition in six developing countries concluded that there was a lack of systematically collected data on indicators reflecting additional aspects of diet quality such as intakes of fruits and vegetables, saturated fat, and processed foods (FAO 2006). The lack of temporal evidence on diets, which could be used to monitor trends, hampers national level efforts to understand and act upon dietary changes which can dramatically impact large proportions of populations.

Translation of these desirable population-level dietary intake goals into easily measurable yet meaningful indicators, which can be used for monitoring trends and evaluating progress of programs, requires additional research. There are more 
complex indices based on 24-h recall or food frequency data, such as the Healthy Eating Index or the Diet Quality Index, however they are seldom employed in the context of developing countries due to the need for more sophisticated dietary intake and food composition data (e.g., to understand the contribution of saturated fat intakes, this element must be present in the food composition data for the food system being analyzed). A number of authors propose greater attention to consideration of the local food environment that could be measured, such as cost of a healthy diet, relative prices of different food groups, biodiversity, and other local level factors influencing food access and consumer choice (Burlingame and Dernini 2012; Igumbor et al. 2012;).

Moving forward there is a need to conduct further research work on how to operationalize some of these additional concepts into indicators which can be measured easily and quickly so that information on diet quality can be collected in a timely fashion and is not too onerous for users to collect and analyze. Another important area of research is about how better use can be made of existing data, both for research and for monitoring. For example, despite their shortcomings household income and expenditure survey data are often widely and regularly available and could be better used to capture household trends in purchasing decisions which may be usefully related and combined with information on the local food environment (cost of fresh and highly processed food items, market accessibility of fresh as compared to highly processed foods).

\section{Measures of women's empowerment}

The need to integrate gender into agricultural research and development, and design interventions specifically to benefit women is not new. We know that women's empowerment is positive for maternal nutrition, and the nutrition of their children and other household members. In Africa, women's control of resources has been linked to larger allocations of resources for food (Doss 2006; Duflo and Udry 2004; Hoddinott and Haddad 1995). Links between maternal resources such as education, work load, and support networks, and child outcomes have been documented in both observational and experimental studies (Cunningham et al. 2014; Quisumbing 2003; Yoong et al. 2012). Progress has been made, but more needs to be done (FAO 2013). The addition of a nutrition objective to agricultural research reinforces the need to pay attention to gender, and identifies specific areas where agriculture-gender-nutrition linkages are likely to be especially strong (Herforth and Harris 2014; Ruel et al. 2013a). Three areas which are important for nutritional outcomes and which can be affected by agricultural interventions are: women's control over resources (assets, inputs, income), women's time burden, and women's energy expenditure. A better understanding of how women's control over resources can influence 
their ability to produce, purchase or otherwise access food and what factors determine their ability to make food choices for themselves and their families is an important area of research. Agricultural development may influence demand for household labor, which could increase women's time burden and have negative effects on child nutrition through reduction in time spent on child care (Kadiyala et al. 2014). Finally, working in agriculture is often physically demanding which can affect women's own nutritional status and that of their children (Herforth et al. 2012).

Agricultural research and development projects should pay careful attention to how they might impact women in these areas, not only if they are seeking to improve agriculture's contribution to nutrition but also to ensure that they do not inadvertently do harm. There is a range of tools and methods for integrating gender in agriculture and for assessing gender disaggregated impact on a range of variables. ${ }^{8}$ Greater use of these tools can provide important evidence on how agricultural interventions can be more nutrition sensitive.

There is also a need for work on more generalizable indicators of empowerment that can be used to monitor change at scale and across different types of interventions and contents. One such indicator that has been developed and is currently in the process of being validated is the women's empowerment in agriculture index (WEAI) (Alkire et al. 2013). Analysis of WEAI data has provided important insights into the gendered considerations of the agriculture to nutrition pathway. Results from Ghana and Nepal have allowed researchers to distinguish which domains of empowerment influence nutritional status and dietary diversity for mothers and children, including the strengths of these impacts, and the differential effects for male and female children. In Ghana, Malapit and Quisumbing (2014) found strong associations between women's empowerment and infant and young child feeding practices, but a much weaker association between women's empowerment and child nutritional status. Empowerment, as measured by women's participation in making decisions about credit, was associated with improved nutritional outcomes for mothers and girls (Malapit and Quisumbing 2014). In Nepal, women's autonomy in agriculture production was associated with multiple outcomes of child nutrition and the mother's own dietary diversity (Malapit et al. 2013). Metrics, like the WEAI, will go far in improving our understanding of how to measure women's empowerment and understand its function in addressing maternal and child dietary diversity and undernutrition.

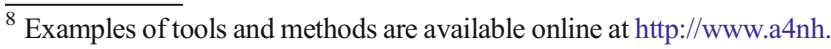
cgiar.org/category/gender-2/gender-nutrition-idea-exchange/ and http:// gaap.ifpri.info/.
}

\section{Re-thinking partnerships in nutrition-sensitive agriculture for development research}

The focus on diet quality and on multisectoral collaboration to reduce stunting has important implications for research partnerships and the partnerships between research and development actors, including the implementing and enabling organizations that will contribute to faster and broader impacts.

For research on improving diet quality and its contributions to reducing stunting, we need new disciplinary partnerships. Traditionally, agricultural research has focused on the farm level, looking at inputs into the farm and outputs from the farm. However, in changing the focus to consumption and demand-side factors, there will be more emphasis on nutrition, marketing, food science, economics, social science, and business sciences. Collaboration among these different disciplines will be increasingly natural as LMIC transform and have a greater proportion of added value in the agri-food sector beyond the farm. Research opportunities in value chain and food system research, including areas such as the efficient production of nutrient-rich foods, nutrition-sensitive food processing, reducing food waste, increasing food safety at different stages of the value chain, and marketing and consumer education strategies to influence healthier food habits are all areas of natural collaboration between agriculture and food science. Technical innovations, particularly frugal innovation for low-cost appropriate technologies for post-harvest will be needed. ${ }^{9}$ Some of these may be adapted from technologies currently available. However even more important are likely to be institutional and social innovations to engage poor people in value chains. Partnerships with business schools, social innovation researchers and others will be critical to support the new mix of needed innovations. Business schools and others will be particularly valuable partners in thinking about metrics and indicators for monitoring, evaluating and adapting value chains in real time to new opportunities.

For improving impacts at scale, the impact pathway and theory of change approach described in the previous section can be extremely valuable for both developing appropriate partnerships and in evaluating and improving the performance of value chains / food systems for delivering diverse and quality diets. For informal and formalizing value chains, theories of change similar to Fig. 2 for improving nutrition and health in animal source food value chains will be useful, emphasizing the importance of partnerships with associations of traders who play a key role in linking farmers to food markets as well as the enabling by policy makers to allow appropriate risk management and quality / price tradeoffs. A good example is the public health risks and enabling policy research for informal milk markets in Kenya (Kaitibie

\footnotetext{
${ }^{9}$ Frugal innovation is a term used to describe products that are redesigned with the demands and constraints of poor consumers in mind and also implies that care was taken to use the least amount of raw materials with the least impact on the environment (The Economist 2010).
} 
et al. 2010). As value chains and food systems become more complex, private sector companies will be more important and the relationship with enabling policy, investment and regulation more complex. In the transition between informal and formal value chains, different types of actors such as non-profit NGOs with a more social-welfare approach or for-profit social enterprises can be useful organizations that can bridge the gap in locations where there are too many risks for regular for-profit businesses. There are also opportunities for novel public-private partnerships to foster and accelerate technical, business, social and policy innovations, such as the Amsterdam Initiative for Malnutrition, Partners in Food Solutions, or the developing Pulse Innovation Partnership mentioned earlier in this paper.

For improving the contribution of agriculture to nutrition outcomes, research partnerships between agriculture and public nutrition are critical. A number of Indian states are good examples of places in which high rates of stunting have persisted together with relatively strong economic and agricultural growth. This so-called agriculture - nutrition disconnect has prompted new partnerships between agriculture, gender and nutrition research for an "agriculture plus" set of interventions including agriculture to improve diet quality and diversity linked to women's empowerment, nutrition education, and behavior change communication (Kadiyala et al. 2014).

With regard to partnerships to evaluate such nutritionsensitive development interventions, researchers need to work closely with development implementers. Over several years, IFPRI has worked closely with Concern Worldwide and Helen Keller International in detailed impact and implementation evaluations of nutrition interventions (Iannotti et al. 2009; Olney et al. 2009; Spielman and Pandya-Lorch 2009). An important partnership question is how to extend the reach of this type of research - implementation partnership to a broader group of non-governmental and even governmental partners. In considering implementation, partnership tools such as net mapping (Schiffer 2007) are very useful in identifying who the key partners are. To strengthen these partnerships, we can again consider these from the perspective of impact pathways and theories of change. Figure 3 shows an impact pathway / theory of change for expanding the reach of research with international NGO program implementers and will allow the testing of partnership performance and assumptions with the goal of enhancing the uptake and use of research findings by development partners.

The major advances in multisectoral nutrition programs and policies in recent times are country-owned and led initiatives, most notably the SUN movement and more recent efforts in the Comprehensive African Agriculture Development Program (CAADP) for agriculture to contribute to nutrition outcomes. This has provided new opportunities for agriculture (and agriculture plus) research teams to support SUN and CAADP country teams in the formulation of strategies and implementation plans. This has worked very well in some
Fig. 3 Theory of Change for use of "evidence" by INGOs in designing and implementing integrated agriculture-nutrition programs. Source: adapted from TANGO 2015, p. 23-25

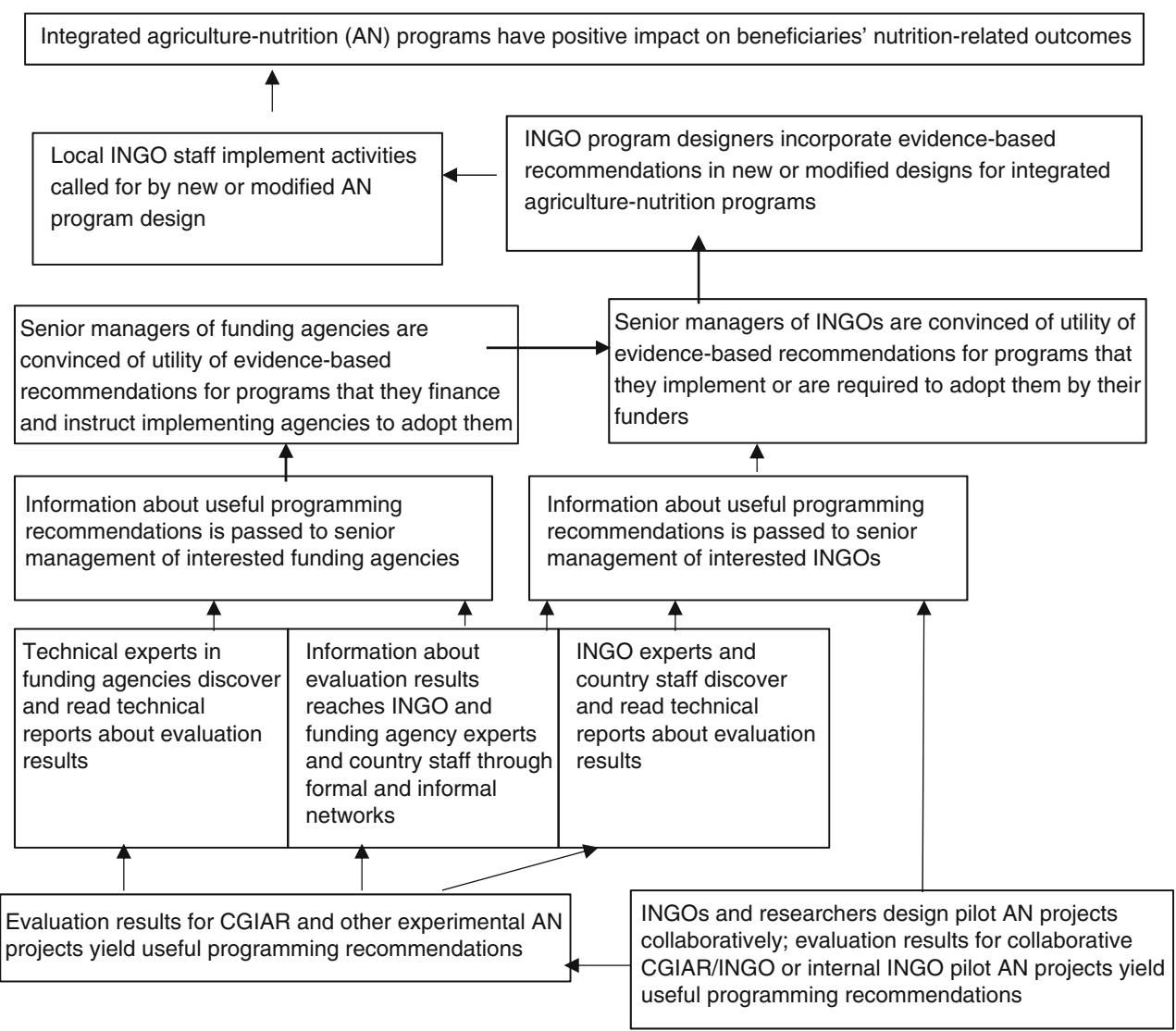


countries such as Zambia. ${ }^{10}$ In many cases, human resource capacity is a major constraint to implementing multisectoral nutrition-specific and -sensitive programs. Again the impact pathways and theories of change can highlight the capacity development requirement (Menon et al. 2013).

In addressing the multisectoral nutrition challenge, the roles of enabling policy, investment and political process are critical. As we learn more about the importance of the enabling environment in achieving nutrition goals, partnerships between researchers and policy makers are essential. The recent Global Nutrition Report (IFPRI 2014) is a good example of such a partnership. This is critical, as research on how policy processes, governance, and champions shape public nutrition has found associations between reduced child stunting and better quality governance, with law and order and the restraint of corruption demonstrating the strongest impact (Smith and Haddad 2014). Nisbett et al. (2014) note how more recent research on nutrition politics has brought greater attention to three important areas of further research - communication of knowledge and evidence on nutrition; political economy and governance of stakeholders; and capacity and use of financial resources. As an example, the authors note that to date there has been no systematic attempt to examine the experience of other sectors that have successfully, and quickly, scaled up treatment and prevention, such as in the case of HIV/AIDs, in order to apply that to nutrition (Nisbett et al. 2014). A more comprehensive review of enabling actions and the partnerships required for those has been published in The Lancet Maternal and Child Nutrition Series (Gillespie et al. 2013).

Finally, how multisectoral partnerships are formed and sustained is a research area in and of itself. There has been a keen interest in multisectoral actions, particularly how these actions are initiated, implemented, and sustained (see examples in Garrett and Natalicchio 2011). The coordination needed for multisectoral actions, given how government, development organizations and private organizations are organized, is complex. Past experiences in integrated development have proven to be very complicated to implement. What we know is that building convergence across sectors requires clear and measurable goals; performance indicators relevant for use at community level; local management of government interventions; and frequent and transparent monitoring of progress toward goals (ISPC 2014).

\section{Conclusion}

Donors, national governments, civil society and private sector entities around the world have all expressed growing interest

\footnotetext{
$\overline{{ }^{10} \text { More details }}$ on Zambia's strategic processes and accomplishments to scale up nutrition, including the Zambia Nutrition Strategy, are available online at http://scalingupnutrition.org/sun-countries/zambia.
}

in changing agriculture and food systems to optimize nutrition outcomes. Many publications have noted the potential for agriculture-food systems to influence nutrition on a large scale, while acknowledging uncertainty about how best to fulfill that potential with equity and environmental sustainability. Demand is high for a new research agenda that can guide agriculture and food investments and policy and program investments towards this end. In this paper we argue that the new nutrition-sensitive agriculture research agenda must start from a focus on consumption of nutritious diets. This will require an in-depth understanding of what drives food (whole diet) consumption choices both from supply and demand perspectives, and how these can be influenced. Agricultural research clearly influences the relative availability and prices (accessibility) of different foods. To ensure that agricultural research contributes to better diets, our research partnerships necessarily need to broaden from a commodity value chain perspective to a broader food systems agenda with contributions from a broader array of expertise. Translation of the new research agenda into policies and programs will require a clear articulation of program impact pathways, theories of change, and an analysis of necessary conditions and cost-effectiveness for scaling-up. A new relationship between researchers, food system implementers and policy makers is needed to guide research and link research more intimately with actions.

The SUN movement, the World Health Assembly, and actions by governments have drawn attention to the economic and human imperatives for preventing stunting and micronutrient deficiencies through country-owned strategies, implementation plans, and policies. Improving diet quality through agriculture and food systems is necessary, but not sufficient for preventing stunting. As part of the broader multisectoral approach to stunting prevention, agriculture plus programs, including gender empowerment, nutrition education, and possibly other elements can make an important contribution. Given the importance of agriculture in many low-income, highburden countries, agriculture can play a catalytic role in the multisectoral nutrition-sensitive programs. As many of the systematic reviews cited in this paper have highlighted, evidence is needed to better inform design, implementation and adjustment of nutrition-sensitive actions. Much greater efforts are needed to fill the evidence gaps but data are lacking. As highlighted in the first Global Nutrition Report (IFPRI 2014), data are unavailable for almost half of countries and for many indicators. Agricultural research can make an important contribution to informing country-led multisectoral actions.

Open Access This article is distributed under the terms of the Creative Commons Attribution 4.0 International License (http:// creativecommons.org/licenses/by/4.0/), which permits unrestricted use, distribution, and reproduction in any medium, provided you give appropriate credit to the original author(s) and the source, provide a link to the Creative Commons license, and indicate if changes were made. 


\section{References}

Alkire, S., Meinzen-Dick, R., Peterman, A., Quisumbing, A. R., Seymour, G., \& Vaz, A. (2013). The women's empowerment in agriculture index. World Development, 52, 71-91.

Arimond, M., Wiesmann, D., Becquey, E., Carriquiry, A., Daniels, M. C., Deitchler, M., et al. (2010). Simple food group diversity indicators predict micronutrient adequacy of women's diets in 5 diverse, resource-poor settings. The Journal of Nutrition, 140(11), 2059S-2069S.

Avula, R., Menon, P., Saha, K. K., Bhuiyan, M. I., Chowdhury, A. S., Siraj, S., et al. (2013). A program impact pathway analysis identifies critical steps in the implementation and utilization of a behavior change communication intervention promoting infant and child feeding practices in Bangladesh. The Journal of Nutrition, 143(12), 2029-2037.

Bank, W. (2014). Learning from World Bank history: Agriculture and food-based approaches for addressing malnutrition. World Bank report number 88740-GLB. Washington, DC: The World Bank.

Berti, P. R., Krasevec, J., \& FitzGerald, S. (2004). A review of the effectiveness of agriculture interventions in improving nutrition outcomes. Public Health Nutrition, 7(5), 599-609.

Black, R. E., Allen, L. H., Bhutta, Z. A., Caulfield, L. E., De Onis, M., Ezzati, M., et al. (2008). Maternal and child undernutrition: global and regional exposures and health consequences. The Lancet, 371(9608), 243-260.

Black, R. E., Victora, C. G., Walker, S. P., Bhutta, Z. A., Christian, P., De Onis, M., et al. (2013). Maternal and child undernutrition and overweight in low-income and middle-income countries. The Lancet, 382(9890), 427-451.

Burlingame, B. \& Dernini, S. (Eds.) (2012). Sustainable Diets and Biodiversity: Directions and Solutions for Policy, Research and Action. Rome: Food and Agricultural Association of the United Nations. http://www.fao.org/docrep/016/i3004e/i3004e.pdf. Accessed 28 August 2014.

Cunningham, K., Ruel, M., Ferguson, E., \& Uauy, R. (2014). Women's empowerment and child nutritional status in South Asia: a synthesis of the literature. Maternal \& Child Nutrition. doi:10.1111/men.12125.

Doss, C. (2006). The effects of intrahousehold property ownership on expenditure patterns in Ghana. Journal of African Economies, 15(1), 149-180.

Dubé, L., Jha, S., Faber, A., Struben, J., London, T., Mohapatra, A., et al. (2014). Convergent innovation for sustainable economic growth and affordable universal health care: innovating the way we innovate. Annals of the New York Academy of Sciences, 1331, 119-141.

Duflo, E. \& Udry, C. (2004). Intrahousehold resource allocation in Cote d'Ivoire: Social norms, separate accounts and consumption choices. Working Paper No. w10498. Cambridge: National Bureau of Economic Research.

FAO. (2003). Proceedings from the measurement and assessment of food deprivation and undernutrition. Rome: Food and Agriculture Organization of the United Nations.

FAO. (2006). The double burden of undernutrition. Case studies from six developing countries. FAO food and nutrition paper 84. Rome: Food and Agriculture Organization of the United Nations.

FAO. (2011). Guidelines for measuring household and individual dietary diversity. Rome: Food and Agriculture Organization of the United Nations.

FAO. (2013). The state of food and agriculture. Rome: Food and Agriculture Organization of the United Nations.

FAO \& IRD. (2014). Defining a standard operational indicator of women's dietary diversity: the women's dietary diversity followup project. Contributors: Y. Martin-Prevel, P. Allemand, D. Wiesmann, M. Arimond, T.J. Ballard, M. Deitchler, M.C. Dop, G. Kennedy, W. T. K. Lee, and M. Moursi. Rome and Montpellier:
Food and Agriculture Organization of the United Nations and Institut de Recherche pour le Développement.

Garrett, J., \& Natalicchio, M. (2011). Conclusion: approaches to working multisectorally in nutrition. In J. Garrett \& M. Natalicchio (Eds.), Working multisectorally in nutrition: principles, practices and case studies (pp. 150-189). Washington: International Food Policy Research Institute.

Garrett, J., Kadiyala, S., \& Kohli, N. (2014). Working multisectorally to improve nutrition: Global lessons and current status in India. POSHAN policy note \#1. New Delhi: International Food Policy Research Institute.

Gillespie, S., Harris, J., \& Kadiyala, S. (2012). The agriculture-nutrition disconnect in India: what do we know? IFPRI discussion paper. Washington: International Food Policy Research Institute.

Gillespie, S., Haddad, L., Mannar, V., Menon, P., \& Nisbett, N. (2013). The politics of reducing undernutrition: building commitment and accelerating progress. The Lancet, 382(9891), 552-569.

Girard, A. W., Self, J. L., McAuliffe, C., \& Olude, O. (2012). The effects of household food production strategies on the health and nutrition outcomes of women and young children: a systematic review. Paediatric and Perinatal Epidemiology, 26(s1), 205-222.

Grace, D., Randolph, T., Olawoye, J., Dipelou, M., \& Kang'ethe, E. (2008). Participatory risk assessment: new approach for safer food in vulnerable African communities. Development in Practice, 18(45), 611-618.

Haddad, L., Nisbett, N., Barnett, I., \& Valli, E. (2014). Maharashtra's child stunting declines: What is driving them? Findings of a multidisciplinary analysis. Brighton: Institute of Development Studies and New York: United Nations Children's Fund. http://www.ids.ac.uk/publication/ maharashtra-s-child-stunting-declines-what-is-driving-them-findingsof-a-multidisciplinary-analysis. Accessed 15 December 2014.

Headey, D. D. (2013). Developmental drivers of nutritional change: a cross-country analysis. World Development, 42, 76-88.

Herforth, A., \& Harris, J. (2014). Understanding and applying primary pathways and principles. Brief\#1 (Improving nutrition through agriculture technical brief series). Arlington: USAID/Strengthening Partnerships, Results, and Innovations in Nutrition Globally (SPRING) Project.

Herforth, A., Jones, A., \& Pinstrup-Andersen, P. (2012). Prioritizing nutrition in agriculture and rural development: guiding principles for operational investments. Health, Nutrition, and Population (HNP) discussion paper. Washington: The World Bank.

Hoddinott, J., \& Haddad, L. (1995). Does female income share influence household expenditures? Evidence from Côte d'Ivoire. Oxford Bulletin of Economics and Statistics, 57(1), 77-96.

Iannotti, L., Cunningham, K., \& Ruel, M. (2009). Improving diet quality and micronutrient nutrition: homestead food production in Bangladesh. IFPRI discussion paper. Washington: International Food Policy Research Institute.

IFPRI. (2014). Global nutrition report 2014: Actions and accountability to accelerate the world's progress on nutrition. Washington: International Food Policy Research Institute.

Igumbor, E. U., Sanders, D., Puoane, T. R., Tsolekile, L., Schwarz, C., Purdy, C., et al. (2012). "Big food", the consumer food environment, health, and the policy response in South Africa. PLoS Medicine, 9(7), e1001253.

ISPC. (2014). Nutrition and health outcomes: Targets for agricultural research. ISPC brief number 43. Rome: CGIAR Independent Science and Partnership Council.

Jha, S. K., McDermott, J., Bacon, G., Lannon, C., Joshi, P. K., \& Dubé, L. (2014). Convergent innovation for affordable nutrition, health, and health care: the global pulse roadmap. Annals of the New York Academy of Sciences, 1331, 142-156.

Johnson, N. (2014). Use of impact pathways and theory of change in A4NH: approach and progress to date. Presentation at the ISPC nutrition workshop, 22-23 September 2014. Independent Science 
and Partnership Council of the CGIAR. http:/www.slideshare.net/ ISPC-CGIAR/johnson-a4-nhispc. Accessed 7 January 2015.

Johnson, N., Guedenet, H., \& Saltzman, A. (2015). What will it take for biofortification to have impact on the ground? Theories of change for three crop-country combinations. IFPRI discussion paper. Washington: International Food Policy Research Institute.

Kadiyala, S., Harris, J., Headey, D., Yosef, S., \& Gillespie, S. (2014). Agriculture and nutrition in India: mapping evidence to pathways. Annals of the New York Academy of Sciences, 1331, 43-56.

Kaitibie, S., Omore, A., Rich, K., \& Kristjanson, P. (2010). Kenyan dairy policy change: influence pathways and economic impacts. World Development, 38(10), 1494-1505.

Kennedy, G., Berardo, A., Papavero, C., Horjus, P., Ballard, T., Dop, M. C., et al. (2010). Proxy measures of household food consumption for food security assessment and surveillance: comparison of the household dietary diversity and food consumption scores. Public Health Nutrition, 13(12), 2010-2018.

Khoury, C. K., Bjorkman, A. D., Dempewolf, H., Ramirez-Villegas, J., Guarino, L., Jarvis, A., et al. (2014). Increasing homogeneity in global good supplies and the implications for food security. Proceedings of the National Academy of Sciences of the United States of America, 111(11), 4001-4006.

Kim, S., Habicht, J.-P., Menon, P., \& Stoltzfus, R. J. (2011). How do programs work to improve child nutrition? Program impact pathways of three nongovernmental organization intervention projects in the Peruvian highlands. IFPRI discussion paper. Washington: International Food Policy Research Institute.

Leroy, J. L., \& Frongillo, E. A. (2007). Can interventions to promote animal production ameliorate undernutrition? The Journal of Nutrition, 137(10), 2311-2316.

Malapit, H. J. L., \& Quisumbing, A. R. (2014). What dimensions of women's empowerment in agriculture matter for nutrition-related practices and outcomes in Ghana? IFPRI discussion paper. Washington: International Food Policy Research Institute.

Malapit, H. J. L., Kadiyala, S., Quisumbing, A. R., Cunningham, K., \& Tyagi, P. (2013). Women's empowerment in agriculture, production diversity, and nutrition: Evidence from Nepal. IFPRI discussion paper. Washington: International Food Policy Research Institute.

Masset, E., Haddad, L., Cornelius, A., \& Isaza-Castro, J. (2012). Effectiveness of agricultural interventions that aim to improve nutritional status of children: systematic review. BMJ, 344, d8222.

Mayne, J., \& Stern, E. (2013). Impact evaluation of natural resource management research programs: A broader view. ACIAR impact assessment series report no. 84. Canberra: Australian Centre for International Agricultural Research.

Menon, P., Rawat, R., \& Ruel, M. (2013). Bringing rigor to evaluations of large-scale programs to improve infant and young child feeding and nutrition: the evaluation designs for the Alive \& Thrive initiative. Food and Nutrition Bulletin, 34(3), S195-S211.

Ng, M., Fleming, T., Robinson, M., Thomson, B., Graetz, N., Margono, C., et al. (2014). Global, regional, and national prevalence of overweight and obesity in children and adults during 1980-2013: a systematic analysis for the global burden of disease study 2013. The Lancet, 384(9945), 766-781.

Nisbett, N., Gillespie, S., Haddad, L., \& Harris, J. (2014). Why worry about the politics of childhood undernutrition? World Development, $64,420-433$.

Olney, D. K., Talukder, A., Iannotti, L. L., Ruel, M. T., \& Quinn, V. (2009). Assessing impact and impact pathways of a homestead food production program on household and child nutrition in Cambodia. Food and Nutrition Bulletin, 30(4), 355-369.

Omore, A. \& Baker, D. (2011). Integrating informal actors into the formal dairy industry in Kenya through training and certification. In International Livestock Research Institute, Towards priority actions for market development for African farmers. Proceedings of an international conference (pp. 281-291). Nairobi: Alliance for a Green Revolution in Africa and International Livestock Research Institute.

Pinstrup-Andersen, P., \& Watson, D. D. (Eds.). (2011). Food policy for developing countries: The role of government in global, national, and local food systems. Ithaca: Cornell University Press.

Popkin, B. M. (2006). Global nutrition dynamics: the world is shifting rapidly toward a diet linked with noncommunicable diseases. The American Journal of Clinical Nutrition, 84(2), 289-298.

Quisumbing, A. R. (Ed.). (2003). Household decisions, gender, and development: A synthesis of recent research. Washington: International Food Policy Research Institute.

Randolph, T. F., Schelling, E., Grace, D., Nicholson, C. F., Leroy, J. L., Cole, D. C., et al. (2007). Invited review: role of livestock in human nutrition and health for poverty reduction in developing countries. Journal of Animal Science, 85(11), 2788-2800.

Rawat, R., Nguyen, P. H., Ali, D., Saha, K., Alayón, S., Kim, S. S., et al. (2013). Learning how programs achieve their impact: embedding theory-driven process evaluation and other program learning mechanisms in Alive \& Thrive. Food and Nutrition Bulletin, 34(3), S212-S225.

Ruel, M. T. (2003). Is dietary diversity an indicator of food security or dietary quality? A review of measurement issues and research needs. Food Nutrition Bulletin, 24(2), 231-2.

Ruel, M. T., Alderman, H., \& Maternal and Child Nutrition Study Group. (2013a). Nutrition-sensitive interventions and programmes: how can they help to accelerate progress in improving maternal and child nutrition. The Lancet, 382(9891), 536-51.

Ruel, M., Harris, J., \& Cunningham, K. (2013b). Diet quality in developing countries. In V. R. Preedy, L. A. Hunter, \& V. B. Patel (Eds.), Diet quality: An evidence-based approach (Vol. 2). New York: Springer.

Schiffer, E. (2007). Net-Map Toolbox: Manual. Washington, DC: International Food Policy Research Institute. http://netmap.files. wordpress.com/2008/06/net-map-manual-long1.pdf. Accessed 18 December 2014

Smith, L., \& Haddad, L. (2014). Reducing child undernutrition: Past drivers and priorities for the post-MDG era. IDS Working Paper 441. London: Institute of Development Studies.

Spielman, D. J., \& Pandya-Lorch, R. (2009). Millions Fed: Proven successes in agricultural development. Washington: International Food Policy Research Institute.

TANGO (2015), Theory of Change on Use of A4NH Research by INGOs: A Study prepared for the CGIAR Collaborative Research Program on Agriculture for Nutrition and Health (A4NH). Unpublished document. A4NH/International Food Policy Research Institute.

The Economist. (2010). First break all the rules: the charms of frugal innovation. The Economist Newspaper Ltd. http://www.economist. com/node/15879359. Accessed 7 January 2015.

UNEG. (2013). Impact evaluation in UN agency evaluation systems: guidance on selection, planning and management, guidance document. New York: United Nations Evaluation Group. http://www. uneval.org/papersandpubs/documentdetail.jsp?doc id=1433. Accessed 13 August 132014.

UNICEF. (1990). Strategy for improved nutrition of women and children in developing countries. A UNICEF policy review. New York: United Nations Children's Fund.

Vorley, B. (2013). Meeting small-scale farmers in their markets: understanding and Improving the institutions and governance of informal agrifood trade. London/The Hague/La Paz: International Institute for Environment and Development / Humanist Institute for Development Cooperation/Mainumby. http://pubs.iied.org/pdfs/ 16548IIED.pdf. Accessed 7 January 2015.

WFP. (2008). Food consumption analysis. Calculation and use of the food consumption score in food security analysis. Prepared by 
VAM unit. Rome: World Food Programme, Vulnerability Analysis and Mapping Branch (ODAV).

White, H. (2009). Theory-based impact evaluation: Principles and practice. Working paper 3. Washington: International Initiative for Impact Evaluation (3ie).

WHO. (2003). Diet, nutrition and the prevention of chronic diseases. Report of a joint WHO/FAO expert consultation. WHO technical report series no. 916. Geneva: World Health Organization.

WHO. (2008). Indicators for assessing infant and young child feeding practices. Part 1: definitions. Conclusions of a consensus meeting held 6-8 November 2007 in Washington. Geneva: World Health Organization.

WHO. (2010). Indicators for assessing infant and young child feeding practices. Part 2: measurements. Conclusions of a consensus meeting held 6-8 November 2007 in Washington. Geneva: World Health Organization.

Yoong, J., Rabinovich, L., \& Diepeveen, S. (2012). The Impact of economic resource transfers to women versus men: A systematic review. Technical report. London: EPPI-Centre, Social Science Research Unit, Institute of Education, University of London.

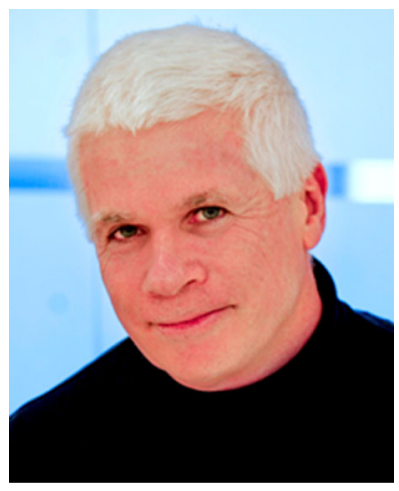

John McDermott John McDermott is the Director of the new CGIAR research program on agriculture for nutrition and health, led by the International Food Policy Research Institute (IFPRI). He has lived and worked in Africa and Asia for 25 years, conducting research on public health and agriculture, particularly in the areas of mixed croplivestock smallholder agriculture and in zoonoses, emerging diseases and food safety. John has a strong background in quantitative methods, is the author or co-author of 200 peer-reviewed publications, book chapters and conference papers and has directly advised over 30 post-graduate students, including $20 \mathrm{PhD}$ graduates.

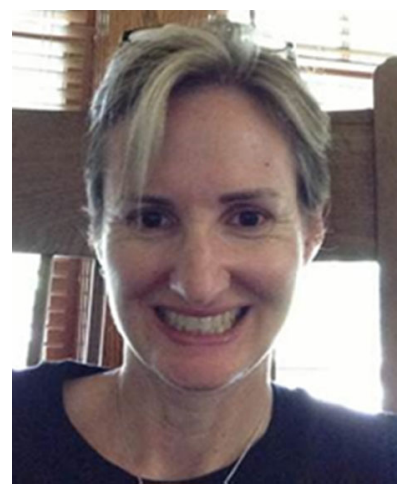

Nancy Johnson Nancy Johnson is an agricultural economist and Senior Research Fellow at the International Food Policy research Institute (IFPRI) where she leads evaluation and impact assessment for the CGIAR Research Program on Agriculture for Nutrition and Health. She studies the economic, poverty and gender impacts of agricultural and natural resource management research and development, and has worked on crop and livestock improvement; land and water management; and institutional innovation in Latin America, Eastern and Southern Africa, and South and SE Asia.

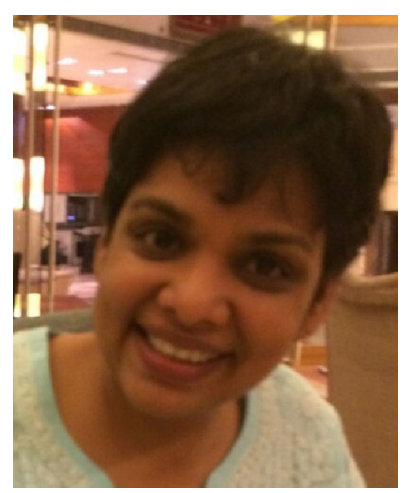

Suneetha Kadiyala Suneetha Kadiyala is a Senior Lecturer in Nutrition-sensitive Development at the London School of Hygiene and Tropical Medicine. She is also a core faculty member of the Leverhulme Centre for Integrative Research on Agriculture and Health (LCIRAH). She has extensive research experience related to HIV, livelihoods and nutrition security in Africa. In India, she established and co-led two large multistakeholder research programs-TANDI (Tackling the Agriculture- Nutrition Disconnect in India) and POSHAN (Partnerships and Opportunities to Strengthen and Harmonize Actions for Nutrition in India). She is the Principal Investigator of IMMANA (Innovative Methods and Metrics for Agriculture and Nutrition Actions), which is designed to stimulate the development and application of scientifically sound methods and metrics in agriculture, health and nutrition research.

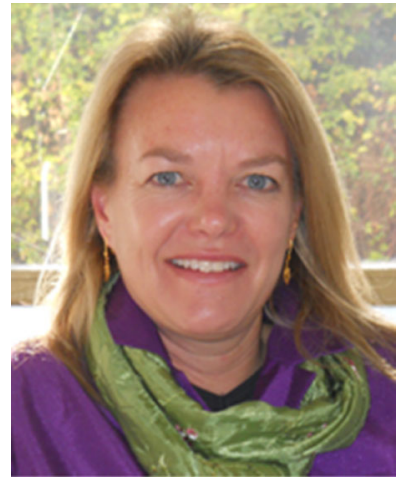

Gina Kennedy Gina Kennedy is a Scientist with the Nutrition and Marketing Diversity Programme of Bioversity International. For the past 10 years she has worked on nutrition assessment in developing countries, including assessing the contribution of agricultural biodiversity on nutrient intake. Prior to joining Bioversity she worked for the Nutrition Division of FAO on food-based indicators for use in food and nutrition security programs, nutrition assessment and nutrient requirements. She has a $\mathrm{PhD}$ in public health nutrition from Wageningen University and her Master of Public Health from the University of Alabama, Birmingham.

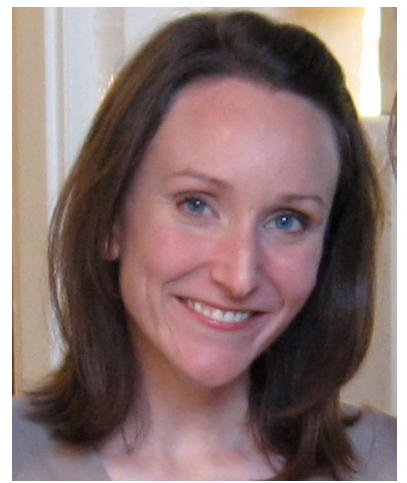

Amanda Wyatt Amanda Wyatt is the program manager for the CGIAR Research Program on Agriculture for Nutrition and Health at the International Food Policy Research Institute. She has been involved in research in the areas of agricultureassociated diseases, gender, and theory-based evaluation methodology of complex programs such as A4NH. Amanda holds a Master of Public Health from Emory University with a focus on global health and public nutrition. During graduate school, she conducted research with the International Livestock Research Institute in Kenya on how dairy development may influence household and young child nutrition in smallholder farming households. 